complete succession. The La Venta ceramics correspond, in fact, to the middle period only of the succession at the neighbouring site of Tres Zapotes. He gives an outline of the distribution of the culture, the centre of which is on the Gulf Coast of the Isthmus of Tehuantepec, showing how closely it is restricted in at least two directions by geographical obstacles. There is reason for believing that its markedly individual and well-known characteristics, which are seen in the sculpture rather than in the pottery, are due to development in place and not to outside stimuli. This conclusion is very important, since it cuts at the root of the idea, recently repeated in Morley's new book on the Maya, that that talented people was the fount of all Central American civilization.

\section{Indian Society for Quality Control}

AN Indian Society for Quality Control, "to promote the advancement and diffusion of knowledge of the science of Quality Control and of its application to industrial processes", has been formed at Calcutta. A committee consisting of engineers, industrialists and statisticians has been set up to conduct the affairs of the Society. Mr. B. K. Rohatgi (director, India Fans, Ltd., and president of the Engineers Association of India) is president, and Prof. P. C. Mahalanobis is among the members of committee. Mr. R. D. Vidyarthi (102-A, Netaji Subhas Road, Calcutta) and Mr. N. T. Mathew (Indian Statistical Institute, Presidency College, Calcutta) are secretaries.

\section{National Research Council of Canada : Publications}

THE second edition (1947) of Publications of the National Research Council of Canada (Ottawa) lists by authors and subjects all papers issued by it up to the end of 1946, these lists merely eiting, however, the serial numbers of the publications in the "N.R.C." series. The major part of the document consists of a serial list of these publications, giving the full title, bibliographical reference if published elsewhere and the price of the reprint or paper in the N.R.C. series, up to number 1412. The Canadian Journal of Research has its own volume and number series, and for this reason is not included in the "N.R.C." series, although reprints of certain papers from it have been included.

\section{Announcements}

Prof. R. C. PunnetT, formerly Arthur Balfour professor of genetics in the University of Cambridge, and Prof. A. H. Sturtevant, professor of genetics in the California Institute of Technology, Pasadena, California, have been elected honorary members of the Genetical Society of Great Britain, in recognition of their outstanding contributions to the science of genetics.

Dr. G. S. HARTLEy has been appointed research manager of Messrs. Pest Control, Ltd., Harston, to take charge of the Chemical Research Department. The company's research programme has for some time been devoted to the development of helicopter spraying, the formulation of aero spray chemicals and the development of selective insecticides to supplement biological control by chemical control on agricultural and horticultural crops in Great Britain, Europe and Africa.

Mr. R. H. Myers, head of the Steelmaking Division of the British Iron and Steel Research Association, has retired on account of ill-health. $\mathrm{H}_{\mathrm{\theta}}$ is succeeded by Dr. A. H. Leckie, formerly deputy head of the Division.

The Challenger Society is prepared to consider applications for small grants in aid of research in marine biology or oceanography at a recognized laboratory during the year June 1948-June 1949. Applications, accompanied by details of the proposed research, should reach the Honorary Secretary, Mr. Dilwyn John, British Museum (Natural History), London, S.W.7, before the end of May.

Applications are invited for the John Gray Jubilee Scholarship of the Society of Chemical Industry, value $£ 150$, tenable for one year at any approved university or technical college. Candidates, who may be of either sex, should be graduates in chemistry whose intention is to enter industry, but those awaiting the result of their final degree exam. ination may apply. Preference will be given to the son of a member of the Society of ten or more years standing. Applications must be made before July 10 to the General Secretary, Society of Chemical Industry, 56 Victoria Street, London, S.W.1.

A Busk studentship in aeronautics will be awarded during June. The studentship is of the value of about $£ 165$, tenable for one year from October 1 ; but a student may be reappointed on the same terms for a second year. It is open to any man or woman being a British subject and of British descent who has not attained the age of twenty-five years on October 1. Forms of application for the studentship, to be returned by June 1, can be obtained from the Professor of Aeronautical Engineering, Engineering Laboratory, Cambridge.

THE first post-war exhibition of German books, periodicals and newspapers from all the occupied zones will be opened by Lord Pakenham on April 19, at 4 p.m., at the Academy Hall, Oxford Street, London, and will remain open for a week. The exhibition is being organised by European Periodicals Publicity and Advertising Co., Ltd., 2, 3 and 5 Studio Place, Kinnerton Street, London, S.W.1, with the view of stimulating the flow of scientific and cultural works from Germany to the rest of the world.

A SHORT course for teachers of chemistry in technical colleges will be held at the Sir John Cass Technical Institute, London, E.C.3, during July 5-16. The main substance of the course will be the theory and practice of micro- and semimicro-inorganic analysis; spectroscopic analysis; small-scale organic preparative methods; electrochemical methods of analysis. There will also be lectures and discussions on teaching methods and recent developments. Visits to works will be arranged. Forms of application may be obtained from any local education authority for further education, or from the Ministry of Education (Short Courses), 14-22 Lennox Gardens, London, S.W.I. The closing date for application is May 15.

WE have received from Messrs. Plant Protection, Ltd., Nobel House, London, S.W.1, a well-produced booklet on their 'Agrocide' range of insecticides. These are based on the synthetic compound 'Gammexane' discovered by Imperial Chemical Industries in 1942. In order that 'Gammexane' may be used in the most economical and efficient manner, Plant Protection have formulated its mixture with powders, solvents, etc. The results described are extremely encouraging and include the control of diverse insect types attacking a wide range of crops in many parts of the world. 